\title{
Introduction to Online Learning issue 21:2
}

\author{
Peter J. Shea \\ University at Albany, State University of New York
}

In this issue of Online Learning we present 10 articles researching MOOCs, administrative and leadership perspectives, faculty issues, and student issues, pedagogy, and support. These papers advance our understanding of online learning with insights from both national and international investigators using quantitative and qualitative approaches to inquiry.

Massive Open Online Courses (MOOCS) remain an area of remarkable growth and interest in online education. The first article in this issue is "Open, Online, and Blended: Transactional Interactions with MOOC Content by Learners in Three Different Course Formats" by Jeffrey P. Emanuel and Anne Lamb of Harvard University. These authors present the first study of its kind in which the same instance of a MOOC was used simultaneously by both tuition-paying, creditseeking students in a blended format and non-paying, non-credit students enrolled exclusively online. The paper identified diverse patterns of participation across these two groups with more homogenous (and limited) engagement by credit seeking students, and either deep or non-existent patterns of engagement among non-credit seeking student. The study provides recommendations for aligning course design with learner motivations in the differing contexts in which students engage with MOOC content.

The MOOC section continues with an article by Jamie Loizzo of the University of Nebraska, and Peggy Ertmer, William Watson, and Sunnie Lee Watson of Purdue University which attempts to provide a more comprehensive, explanatory account of MOOCs. In "Adult MOOC Learners as Self-Directed: Perceptions of Motivation, Success, and Completion" the authors investigate the perspectives of learners rather than those of administrators or faculty, as has been more common in prior research. Using interviews with a dozen participants in a recent MOOC the authors provide a deeper conceptual explanation of the adult learner MOOC experience. They do this by organizing the results into a framework that illustrated the similarities and differences in the subjects' perceptions of motivation, success, and completion. This framework may be useful to educators and instructional designers who develop and facilitate distance education environments, communities of practice, and social learning networks for adult learners.

The next section of the issue contains a new national study of online learning leaders by Eric Fredericksen of the University of Rochester. As online education continues to grow and mature it is increasingly common to have a single designated senior administrator to oversee efforts at the institutional level. In this paper the author does some of the important early work needed to identify and describe characteristics of these leaders, their institutional context, and the nature of their experience and qualifications. The paper begins to shed light on this new role and helps senior leaders to better situate and benchmark their institutional strategic goals and efforts in online education. 
The following section contains two articles on faculty issues and concerns. The first is "Challenging Teachers' Pedagogic Practice and Assumptions about Social Media" by Helen Cartner and Julia Halla of Auckland University of Technology in New Zealand. In this study the authors address the issue of changing not only teacher knowledge of new technologies but also their practices. They propose to accomplish this by forgoing a technology-centric approach and substituting a guided, reflective, constructivist approach to professional development. In the paper the authors describe the process by which by which they encourage teachers to make a conceptual shift from what the teacher is doing to what the learner is doing during the learning and teaching process. They conclude that teachers do alter their assumptions about using social media and teaching practice after they engage in professional development activities that challenge their existing mental models.

The next article in this section is "Building Community in Online Doctoral Classrooms: Instructor Practices that Support Community" by Sharla Berry of the University of Southern California. In this paper the authors seeks to understand the faculty role in the development of community in a synchronous, online doctoral program in Education. Using qualitative data collection and analyses from course transcripts and interviews with students the authors conclude that faculty in the program studied here who create a warm and welcoming tone, use technology to create a personalized learning experience, and employ tools to engage all learners are more likely to develop a sense of community among students conducive to doctoral level education. Those developing new doctoral programs should take note.

The final section of this issue contains five articles on themes associated with students including formal and informal assessment of learning, cooperative learning approaches, selfregulation, and advisement. The first article in this section is "Exploring Digital Badges in University Courses: Relationships between Quantity, Engagement, and Performance" by Joseph Fanfarelli and Rudy McDaniel of the University of Central Florida. Arguing that digital badging is gaining momentum in higher education and using correlational methods with a small number of students in an exploratory study, these authors ask whether there is a significant correlation between the number of badges earned by a student and the learning outcomes expressed in the final grade in a course. These initial results suggest that badges are correlated with final grades and that stronger correlations exist among certain subgroups. The authors conclude that additional research is warranted to see if results are replicated with a larger sample and more rigorous designs that rule out pre-existing differences that may explain these early findings.

Are there simple, agreed-upon criteria by which to evaluate good teaching and learning in higher education contexts? With more than 6500 citations, one set of guidelines that has long been recognized is Chickering and Gamson's seven principles of good practice in undergraduate education. This concise framework reflects recommendations from a broad range of research conducted over decades. But do more recent efforts to assess online pedagogy in higher education align with these well-known principles? In "Evaluation Instruments and Good Practices in Online Education" Sally Baldwin and Jesus Trespalacios of Boise State University address this question by conducting a comprehensive review of the literature and analyzing twenty-eight different evaluation instruments currently used to design and review online courses in higher education. The collection of these instruments is highly useful and the authors do find differences among them relating to the inclusion of each of the seven principles. This article will be of interest to 
those seeking to ensure they have the right criteria in efforts to assess the quality of course design and instruction in online settings.

Students in online courses can struggle with the need to be more proactive, independent, and reflective in the absence of face-to-face interaction and the familiarity of classroom settings. These challenges can be grouped under the construct of self-regulation. In "Promoting College Student Self-Regulation in Online Learning Environments" Jacob Wandler and William John Imbriale of Michigan State University summarize the concept of a self-regulation, discuss its importance in undergraduate online courses, and review strategies that faculty can adopt to improve learner self-regulation in online college courses. This paper is useful for instructional designers and faculty seeking to improve their courses.

In "An Investigation into Cooperative Learning in a Virtual World using Problem-Based Learning" authors Vanessa Parson of the University of Sunderland and Simon Bignel of the University of Derby in the United Kingdom examine the use of Problem Based Learning (PBL) in in a Multi User Virtual Environment (MUVE). Citing the strong research base for this pedagogic approach and the complimentary nature of MUVEs for recreating a real-world environment useful for enacting PBL, the authors developed and tested a simulation in Second Life as a potential environment for online teaching and learning combining PBL and MUVEs. The consensus among the 19 higher education educators studied here was that the experience provided more immersion and engagement than traditional methods leading to potentially improved learning. The authors also provide qualitative analysis along four identified themes including technical issues, immersion, potential, and pedagogy. This study augments evidence from previous work conducted in pre-college settings adding to the possibilities of using PBL in higher education online settings.

The final paper in this issue looks at student challenges from yet another perspective asking how online students perceive virtual support from technology systems and faculty. In "Student Attitudes toward Technology-Mediated Advising Systems" by Hoori Santikian Kalamkarian and Melinda Mechur Karp of the Community College Research Center at Teachers College, Columbia University the authors examined focus group interview data from 69 students at six colleges to investigate their perceptions about online advising. The study looks at how students' attitudes and experiences vary across different aspects of advising. The study concludes that students are more accepting of technology for more routine tasks, such as course registration, but prefer face-to-face support for more complex tasks, such as planning courses for multiple terms and refining their academic and career goals. These findings help program developers, faculty, and student support staff with planning, policy, and implementation of more student-centered online programs.

We invite you to read, share, and cite these articles and to help us to continue to advance the field of online learning.

\section{References}

Baldwin, Sally J. \& Trespalacios, Jesús (2017). Evaluation instruments and good practices in online education. Online Learning 21 (2) doi: 10.24059/olj.v21i2.913

Berry, Sharla (2017). Building community in online doctoral classrooms: instructor practices that support community. Online Learning 21 (2) doi: 10.24059/olj.v21i2.875 
Cartner, Helen C. \& Hallas, Julia L. (2017). Challenging teachers' pedagogic practice and assumptions about social media. Online Learning 21 (2) doi: 10.24059/olj.v21i2.1009

Emanuel, Jeffrey P. \& Lamb, Anne (2017). Open, online, and blended: transactional interactions with MOOC content by learners in three different course formats, Online Learning 21 (2) doi: $10.24059 /$ olj.v21i2.845

Fanfarelli Joseph R. \& McDaniel, Rudy (2017). Exploring digital badges in university courses: relationships between quantity, engagement, and performance. Online Learning 21 (2) doi: 10.24059/olj.v21i2.1007

Fredericksen, Eric E. (2017). A national study of online learning leaders in US higher education, Online Learning 21 (2) doi: 10.24059/olj.v21i2.1164

Kalamkarian, Hoori Santikian \& Karp, Melinda Mechur (2017) Student attitudes toward technology-mediated advising systems. Online Learning 21 (2) doi:

10.24059/olj.v21i2.918

Loizzo, Jamie, Ertmer, Peggy A., Watson, William R., \& Watson, Sunnie Lee (2017). Adults as self-directed and determined to set and achieve personal learning goals in MOOCs: learners' perceptions of MOOC motivation, success, and completion. Online Learning 21 (2) doi: 10.24059/olj.v21i2.889

Parson, V. \& Bignel, S. (2017). An investigation into cooperative learning in a virtual world using problem-based learning, Online Learning 21(2) doi: 10.24059/olj.v21i2.796

Wandler, J. \& Imbriale, W. J. (2017) Promoting college student self-regulation in online learning environments, Online Learning 21 (2) 10.24059/olj.v21i2.881 